\title{
FEA Analysis of Tvs Sport Alloy Wheel Rim with Various Speed
}

\section{P.S.Mohanasaravanan ${ }^{1}$, B.Vikram ${ }^{2}$, M.K.Karthik ${ }^{3}$}

1, 2, 3 Assistant Professor, Department of Aeronautical Engineering, Bharath Institute of Higher Education and Research, Chennai.

Article History: Received: 11 January 2021; Accepted: 27 February 2021; Published online: 5 April 2021

ABSTRACT: The work is to analysis the structural stability and strength of a low budget Indian two wheeler TVS Sport bike alloy wheel rim in high speed conditions, the alloy wheel rim is holding the tyre and stability of the vehicle, the ANSYS Structural Analysis carried out for various RPM like 500, 1000, 1500 and 2000 RPM the results of stress, strain and deformation results taken for various materials like steel, aluminium and polypropylene KEYWORDS: TVS Sport, Alloy Wheel rim, Steel, Aluminium, Polypropylene, ANSYS Static Structural

\section{INTRODUCTION:}

Now a days, mostly of the automobiles wheel rim is made up of Magnesium or aluminium or alloy of magnesium and aluminium. When comparing alloy with steel wheel, alloy wheel has lesser in weight, so it has better fuel efficiency. Dissipation of heat in an alloy which increase the braking of system. Most of the automobile wheel is made of aluminium and alloys of aluminium. Rim of the automobile must withstand static and fatigue loads.

Rim of the wheel must design as efficient as possible to withstand load as well as lighter in weight. In this analysis focused on different material used in the rim of the automobile wheel and compare those materials. This work is focused rim wheel of TVS Sport. This analysis focused to compare the result obtained on three materials such as steel, Aluminium and Polypropylene. The result such as total deformation, strain and stress occur during those material with three different rotational speed of

\section{Materials and methods}

Steel

A kind of alloy obtain from the iron is contain a different ratio of carbon content is steel, it has a characteristic of high strength and high resistance to fracture. If it is stainless steel it has high corrosive resistance in nature. Stainless steel has chromium combination along with the carbon content.

\section{Aluminium}

Aluminium is very light in weight and it can obtain easily in earth. In earth aluminium we can obtain easily compare to other material except oxygen and silicon. This may be the reason to choose the aluminium is used for most of the application. In this work also consider aluminium as one of material for analysis.

\section{Polypropylene}

Polypropylene (PP), It can also refer as polypropene, Polypropene is coming under the type of thermoplastic polymer.

Table 1. Material Properties

\begin{tabular}{|c|c|c|c|}
\hline & $\begin{array}{c}\text { DENSITY } \\
\left(\text { KG/M }^{\mathbf{3}}\right)\end{array}$ & $\begin{array}{c}\text { YOUNG'S } \\
\text { MODULUS(GPA) }\end{array}$ & $\begin{array}{c}\text { POISSON'S } \\
\text { RATIO }\end{array}$ \\
\hline STEEL & 7850 & $200 \mathrm{GPA}$ & 0.28 \\
\hline ALUMNIUM & 2700 & $70 \mathrm{GPA}$ & 0.3 \\
\hline POLYPROPYLENE & 920 & 1.325 & 0.44 \\
\hline
\end{tabular}

\section{Finite Element Modelling}

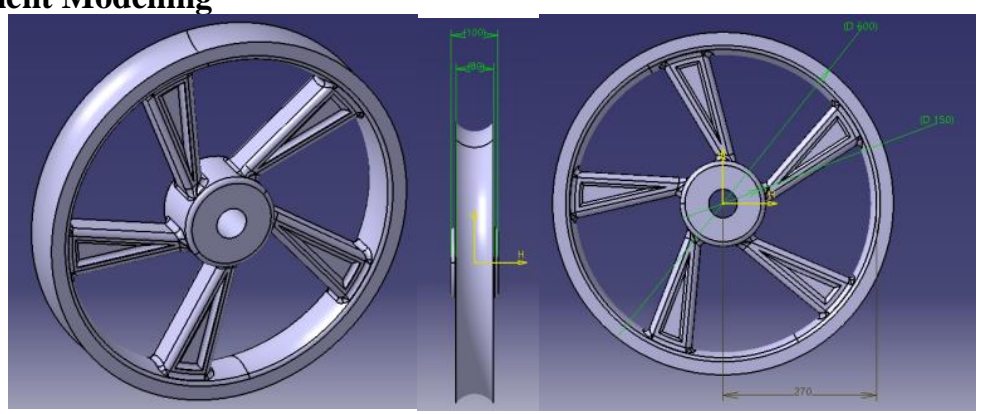


Fig 1. 3D Model and Dimensions of TVS Sport Alloy Wheel Rim

The design of TVS Sport Alloy three dimensional wheel rim model is done in CATIA V5 software with the commands of Pad, pocket, fillet and pattern commands with the diameter of $600 \mathrm{~mm}$ and width of $100 \mathrm{~mm}$ Mesh and Boundary conditions

For the Finite element analysis discretization process will give the better results with the nodes of 419068 and tetrahedral elements of 248399 The boundary conditions of this alloy wheel analysis is various rotational speed of 500rpm, 1000rpm, 1500rpm and 2000rpm was given for this analysis

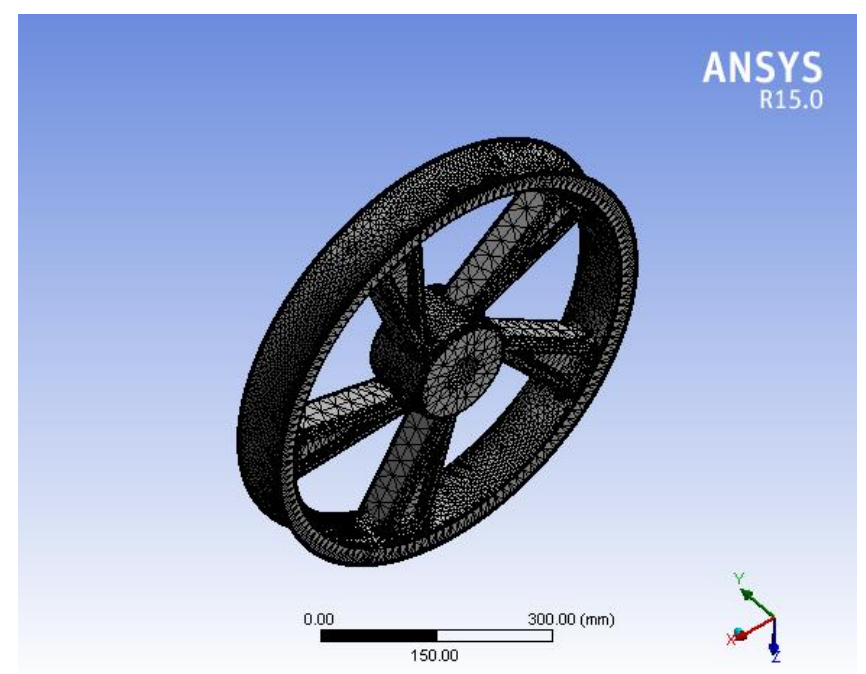

Fig 2. Mesh Model of the TVS Sport Alloy wheel Rim

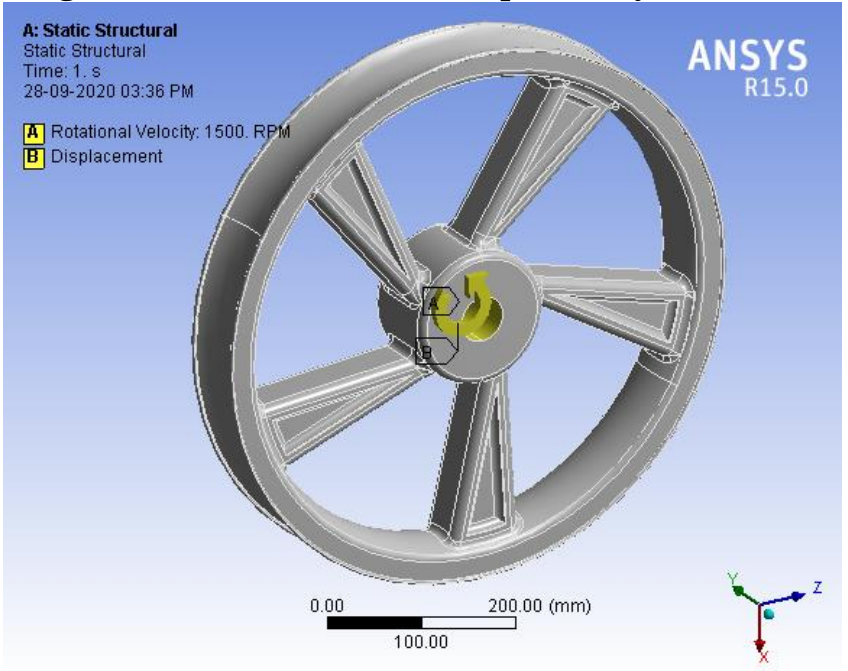

Fig 3. Boundary Conditions for structural analysis

\section{RESULTS AND DISCUSSIONS}

TOTAL DEFORMATION RESULTS.

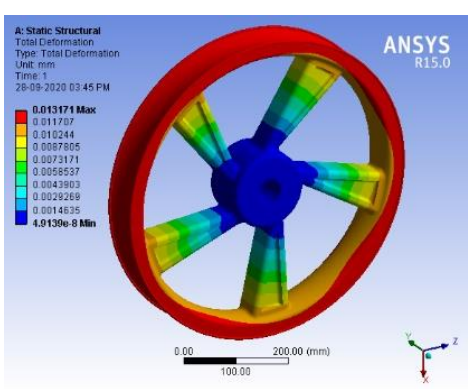

STEEL
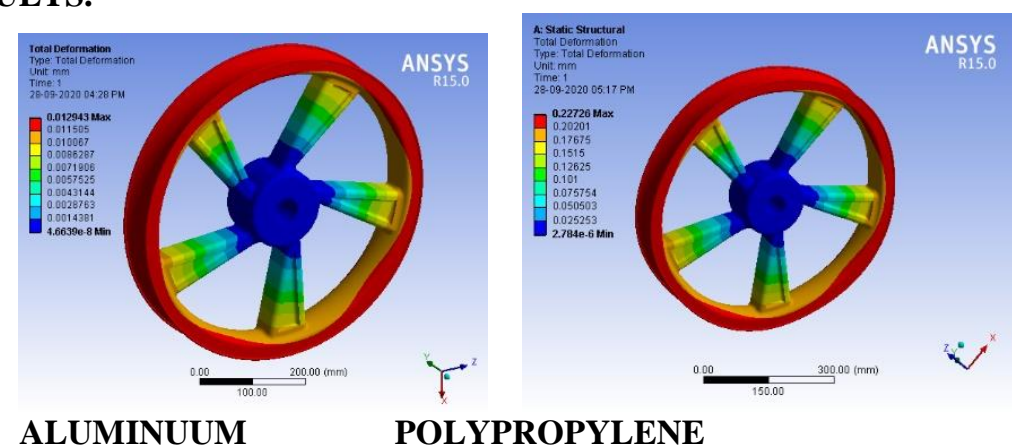
Fig 4. Comparison of deformation results of 500 RPM TVS sport Alloy wheel rim

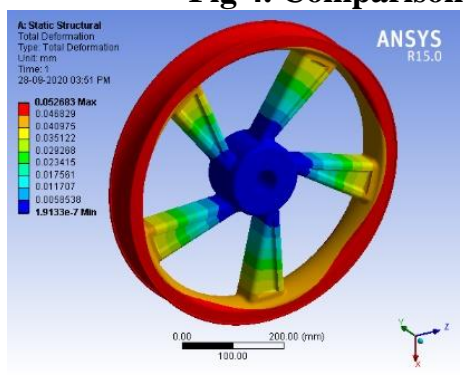

STEEL

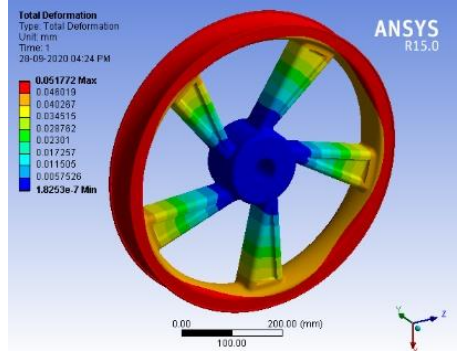

ALUMINUUM

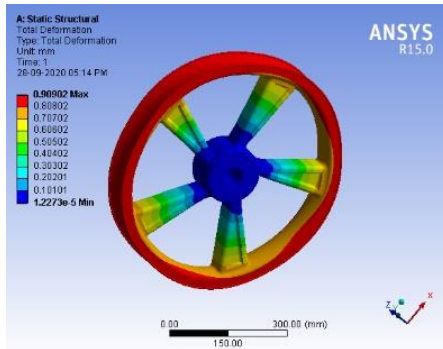

POLYPROPYLENE

Fig 5. Comparison of deformation results of 1000 RPM TVS sport Alloy wheel rim

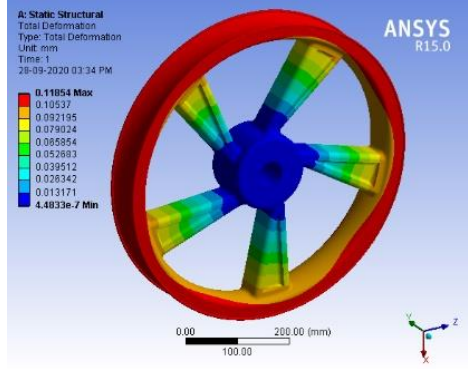

STEEL
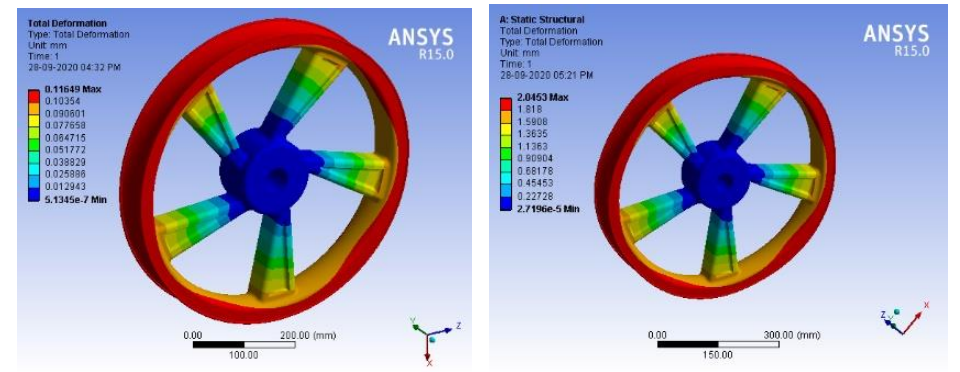

POLYPROPYLENE

Fig 6. Comparison of deformation results of 1500 RPM TVS sport Alloy wheel rim

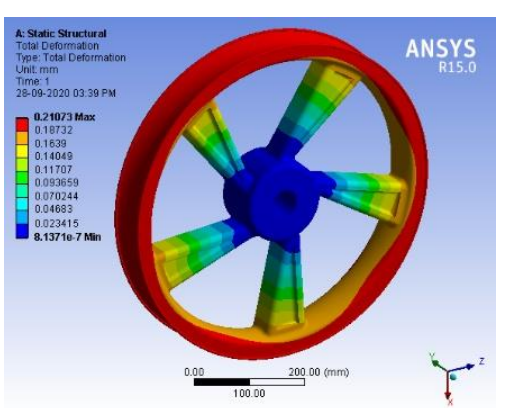

STEEL
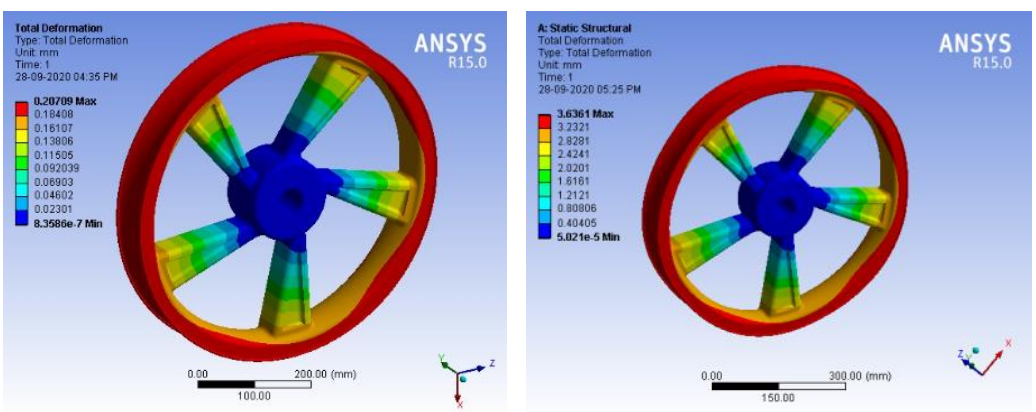

POLYPROPYLENE

Fig 7. Comparison of deformation results of 2000 RPM TVS sport Alloy wheel rim

Table 2. Total Deformation Results

\begin{tabular}{|c|c|c|c|c|}
\hline $\begin{array}{c}\text { TOTAL } \\
\text { DEFORMATION(mm) }\end{array}$ & 500 RPM & $1000 \mathrm{RPM}$ & 1500RPM & 2000RPM \\
\hline STEEL & 0.013171 & 0.052683 & 0.11854 & 0.21073 \\
\hline ALUMINIUM & 0.012943 & 0.051772 & 0.11649 & 0.20709 \\
\hline POLYPROPOLYN & 0.22726 & 0.90902 & 2.0453 & 3.6361 \\
\hline
\end{tabular}

\section{TOTAL STRAIN RESULTS}

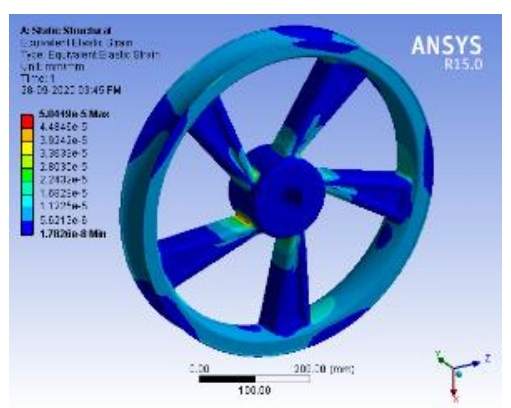

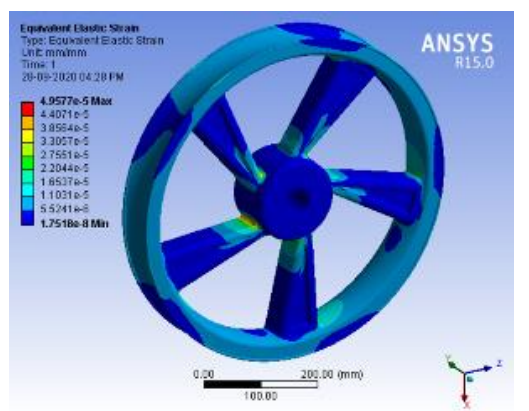

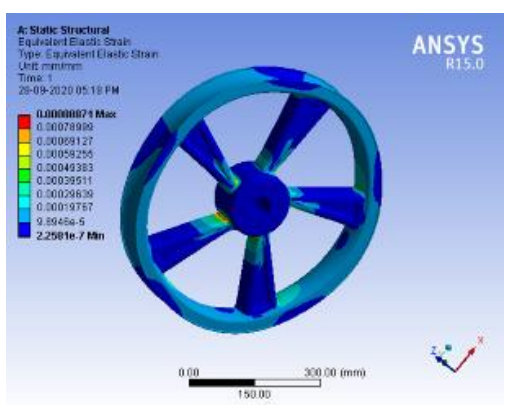


POLYPROPYLENE

Fig 8. Strain Results for 500 RPM Alloy wheel rim
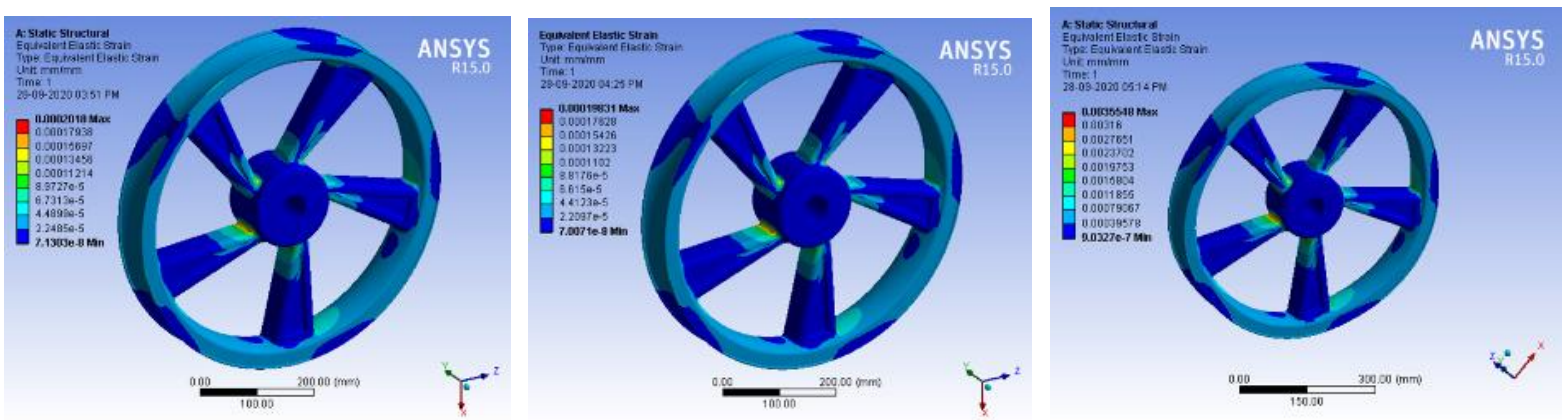

STEEL

ALUMINUUM

POLYPROPYLENE

Fig 9. Strain Results for 1000 RPM Alloy wheel rim
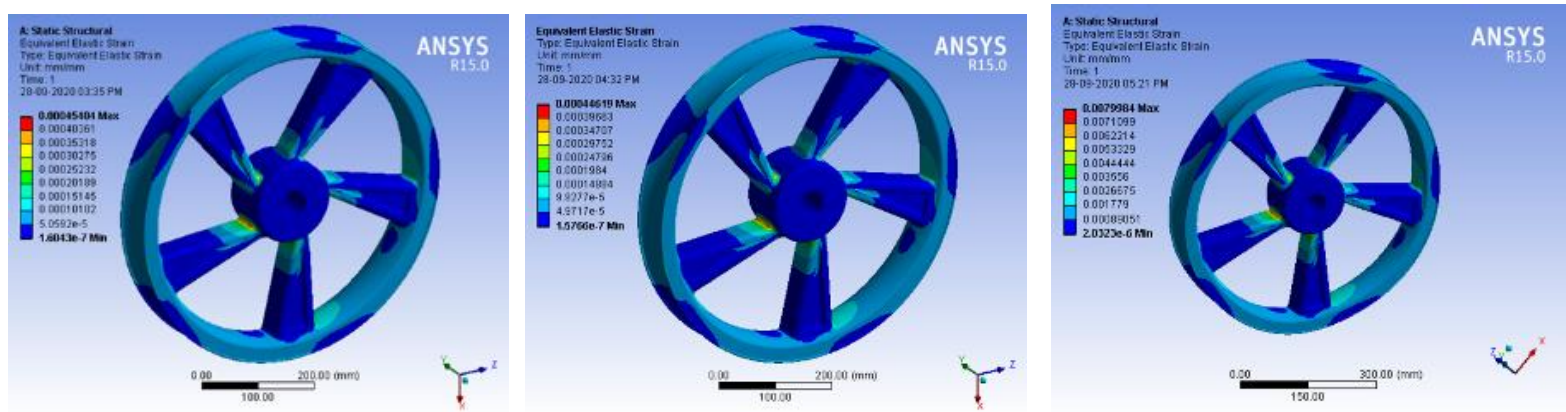

STEEL

ALUMINUUM

POLYPROPYLENE

Fig 10. Strain Results for 1500 RPM Alloy wheel rim

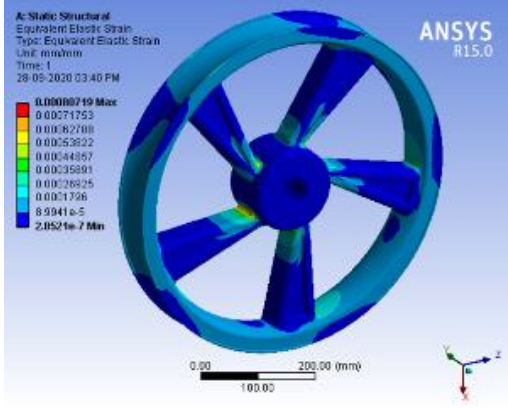

STEEL

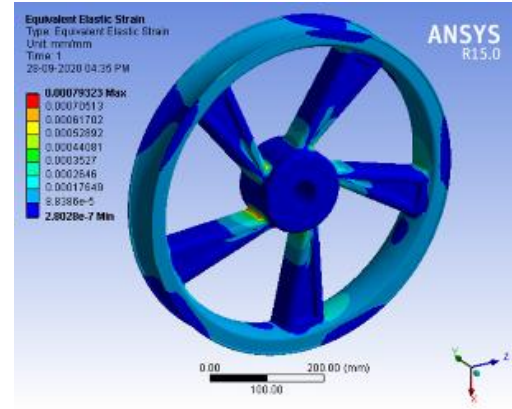

POLYPROPYLENE

ALUMINUUM

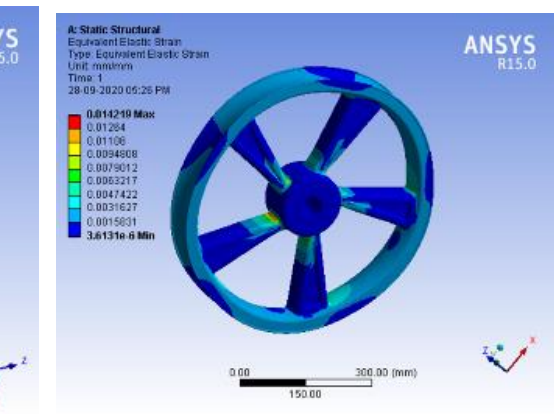

Fig 11. Strain Results for 2000 RPM Alloy wheel rim

Table 2. Strain Results

\begin{tabular}{|c|c|c|c|c|}
\hline TOTAL STRAIN & 500RPM & $1000 \mathrm{RPM}$ & $1500 \mathrm{RPM}$ & $2000 \mathrm{RPM}$ \\
\hline STEEL & 5.0449 & 0.000202 & 0.000454 & 0.000807 \\
\hline ALUMINIUM & 4.9577 & 0.000198 & 0.000446 & 0.000793 \\
\hline POLYPROPOLYN & 0.000889 & 0.003555 & 0.007998 & 0.014219 \\
\hline
\end{tabular}




\section{TOTAL STRESS RESULTS}
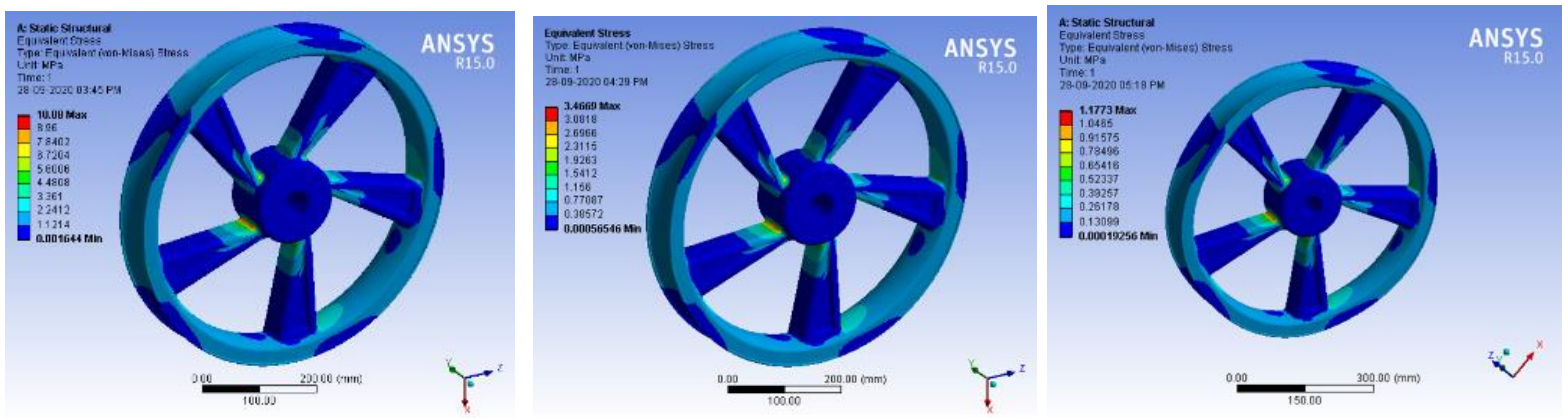

STEEL

ALUMINUUM

POLYPROPYLENE

Fig 12. Stress Results for 500 RPM Alloy wheel rim

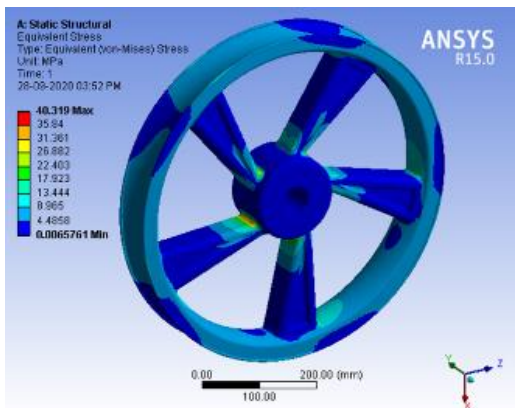

STEEL

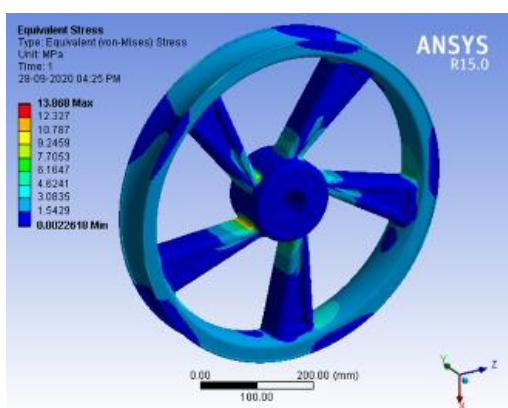

POLYPROPYLENE

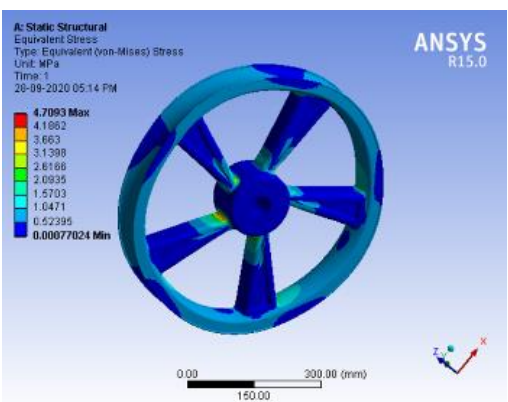

ALUMINUUM

Fig 13. Stress Results for 1000 RPM Alloy wheel rim

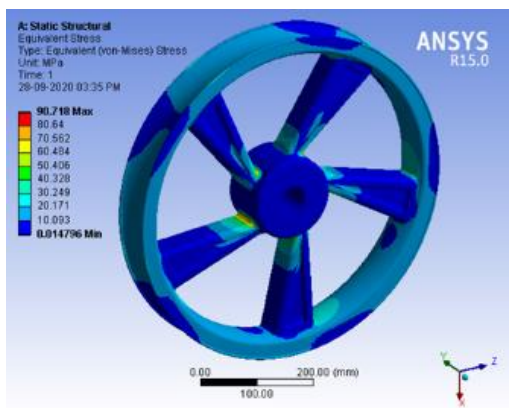

STEEL
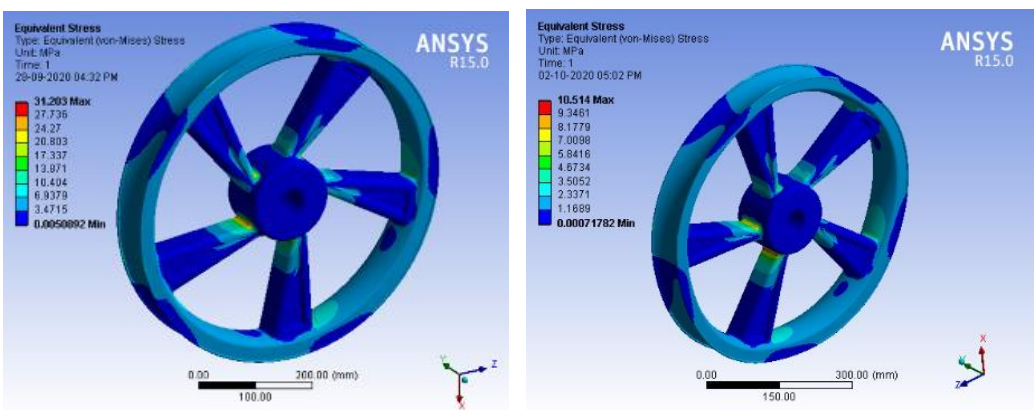

ALUMINUUM

POLYPROPYLENE

Fig 14. Stress Results for 1500 RPM Alloy wheel rim
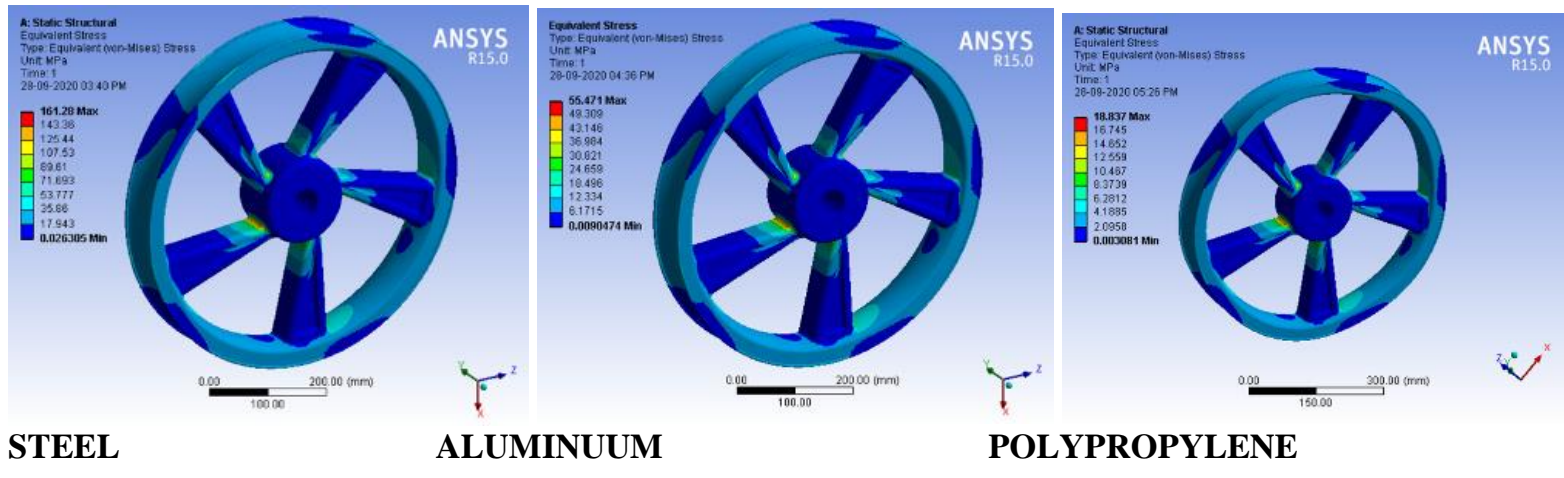

POLYPROPYLENE

Fig 15. Stress Results for 2000 RPM Alloy wheel rim 
Table 2. Stress Results

\begin{tabular}{|c|c|c|c|c|}
\hline TOTAL STRESS & 500RPM & 1000RPM & 1500RPM & 2000RPM \\
\hline STEEL & 10.08 & 40.319 & 90.718 & 161.28 \\
\hline ALUMINIUM & 3.4669 & 13.868 & 31.203 & 55.471 \\
\hline POPYPROPOLYNE & 1.1773 & 4.7093 & 10.514 & 18.837 \\
\hline
\end{tabular}

\section{Conclusion:}

The TVS Sport Alloy wheel rim analysis done in ANSYS Static Structural Software, Three dimensional model of TVS sport alloy wheel is done in CATIA V5 and the analysis results taken for various materials Steel, Aluminium and Polypropylene Materials, The better structural stability obtained from the Polypropylene materials, if we go to use TVS Sport bike in high speed conditions Polypropylene frame is the better material

\section{References:}

1. T. Siva Prasad,T. Krishnaiah, J. Md. Iliyas, M.Jayapal Reddy, “A Review on Modeling and Analysis of Car Wheel Rim using CATIA \& ANSYS", International Journal of Innovative Science and Modern Engineering (IJISME) May 2014, Volume-2, Issue-6, ISSN: 2319-6386.

2. Sourav Das, (CAE Analyst), "Design and Weight Optimization of Aluminum Alloy Wheel", International Journal of Scientific and Research Publications, June 2014, Volume 4, Issue 6, ISSN 2250 3153.

3. S.Ganesh, Dr.P.Periyasamy, "Design and Analysis of Spiral Wheel Rim for Four Wheeler", The International Journal Of Engineering And Science (IJES), 2014, Volume 3, Issue 4, Pages, 29-37.

4. P. Meghashyam1, S. Girivardhan Naidu and N. Sayed Baba, "Design and Analysis of Wheel Rim using CATIA \& ANSYS", International Journal of Application or Innovation in Engineering \& Management (IJAIEM) August 2013, Volume 2, Issue 8,

5. Ravi Lidoriya, SanjayChaudhary and Anil Kumar Mohopatra, "Design and Analysis of AluminiumAlloyWheel using PEEK Material", International Journal of Mechanical Engineering and Research. (2013), Volume3, Number5, ISSN No. 2249-0019, pp. 503-516

6. P. RamamurtyRaju, B. Satyanarayana , K. Ramji, K. Suresh Babu, "Evaluation of fatigue life of Aluminum alloy wheels under radial loads", November 2006.

7. XiaofengWanga, XiaogeZhang," Simulation of dynamic cornering fatigue test of a steel Passenger car wheel", International Journal of Fatigue 32 (2010), 